\title{
Intense events of rainfalls in Piemonte
}

\author{
Marco Casazza and Angelo Piano \\ Dipartimento di Fisica Generale «A. Avogadro», Università di Torino, Italy
}

\begin{abstract}
The possibility of studying the precipitations recorded in a large number of meteorological stations in Piemonte led us to analyse what has happened in the last century. A comparison between periods of 10-20 years, using an arbitrary index of rainfall, shows an increase in intense events in the last 20 years though we can observe a general reduction, in absolute value, of the quantity of rain. It is shown that, in the last 30 years, there has been a change in the granulometric distribution of Suspended Particulate Matter (SPM) which, in standard conditions, might become Condensation Nuclei $(\mathrm{CN})$. This might have influenced condensation phenomenon, causing a greater frequency of intense events.
\end{abstract}

Key words precipitation - intense events - inorganic particulate matter

\section{Introduction}

Recent natural events of great intensity and their frequency have aroused the attention of atmospheric physicists (Diodato, 1999) who, individually, have suggested different hypotheses to explain what has happened.

Luckily, precipitations have been studied for a long time in Italy for three main reasons: the first is linked to Fr. Angelo Secchi of Reggio Emilia, who lived in the 19th century and promoted, in 1886, the creation of a National Meteorological Service; the second is due to the easiness of measuring rainfalls; the third is the danger of this phenomenon, that persuaded many people to accept floods as unavoidable events.

We have a great quantity of data relative to our Region in the last century. Our «Dipartimento di Fisica Generale» has two meteorological stations in Torino. The aim of this work is to obtain an index of pluviometric intensity to characterise different periods and, particularly, the last 20 years.

Mailing address: Dr. Angelo Piano, Dipartimento di Fisica Generale «A. Avogadro», Università di Torino, Via P. Giuria 1, 10125 Torino, Italy; e-mail: piano@to.infn.it

\section{Pluviometry in Piemonte}

In our Region, rain distribution shows a greater regularity in the plains. The absolute maxima are located in the interface between the mountains and the plains, with a decrease going to inner mountain regions. The mountainous areas having poor rainfalls are, in fact, the inner western alpine valleys: Val Susa, Varaita and Maira (with mean precipitations per year not exceeding $900 \mathrm{~mm}$ ). The same tendency is more evident in the northern valleys (in Val d'Ossola we go from mean values of $2300 \mathrm{~mm}$ to $1200 \mathrm{~mm}$ ). This phenomenon is due to the obstruction created by the first relieves close to the plain that stops a portion of air masses from the southern quadrant.

In the interface with the plains, we can find the places with greatest precipitations. The most important area goes from Lago Maggiore to Valli di Lanzo (with a yearly maximum of $2350 \mathrm{~mm}$ in Cicogna (VB)). The second one is in the SE of the Region, close to the borders Piemonte, Liguria, Lombardia and Emilia Romagna (Scrivia and Curone basins). The third area is close to Maritime Alps, from the southern plain of the «Provincia» of Cuneo and from the Langhe to the mountains between Valle Gesso and Tanaro. The last one is referred to as the Prealps between Val Chisone and Val Pellice. In this cases, the abundance of rainfalls is due to 
the air masses coming from the plain, which, rising, discharge their humidity. In the second and third cases, instead, precipitations are linked with the presence of the sea; in fact, having winds from S-SE (from Genova), humid currents cross this area. The lowest precipitation levels are in the plain areas close to the Apennines. The best condition for having rain in our Region is to have air currents from $\mathrm{S}$ or SE; the leeward area of the Maritime Alps receives the air poor in humidity, so it is characterised by a small amount of rainfalls. All the other plain areas are crossed by more humid air masses. That is why the northern plains are the rainiest ones.

\section{Number of days of rain and mean intensity}

The number of days of rain in a year goes from a minimum, typical of the Mediterranean region, of 50 to a maximum, of a continental type, of 140. The areas having fewer events (less than 70 per year) are the Monferrato and a portion of Langhe. In the plain regions we can go, usually, from 70 to 90 days while, in the relieves, we do not exceed 90 days, with a small area of Toce basin, where we exceed 110 days per year.

The values of daily precipitations, obtained dividing the mean annual value by the number of rainy days, go from 8 to $24 \mathrm{~mm} /$ day. Usually the mean intensity value in our Region goes from 10 to $15 \mathrm{~mm} /$ day. Areas with lower intensities (less than $10 \mathrm{~mm} /$ day) are located around Alessandria and the inner Alpine Valleys. The greatest ones, instead, are in the areas characterised by abundant yearly rain; this is due more to the intensity than to the number of rainy days. That is why it is important to find an index that is not influenced by local phenomena.

\section{Choices}

Because of the distribution in our Region and because of the validation of data, we have privileged, the measurement points considered in the Annali Idrologici. Among all the possible stations available, for different reasons (absence of historical data, lack of long periods

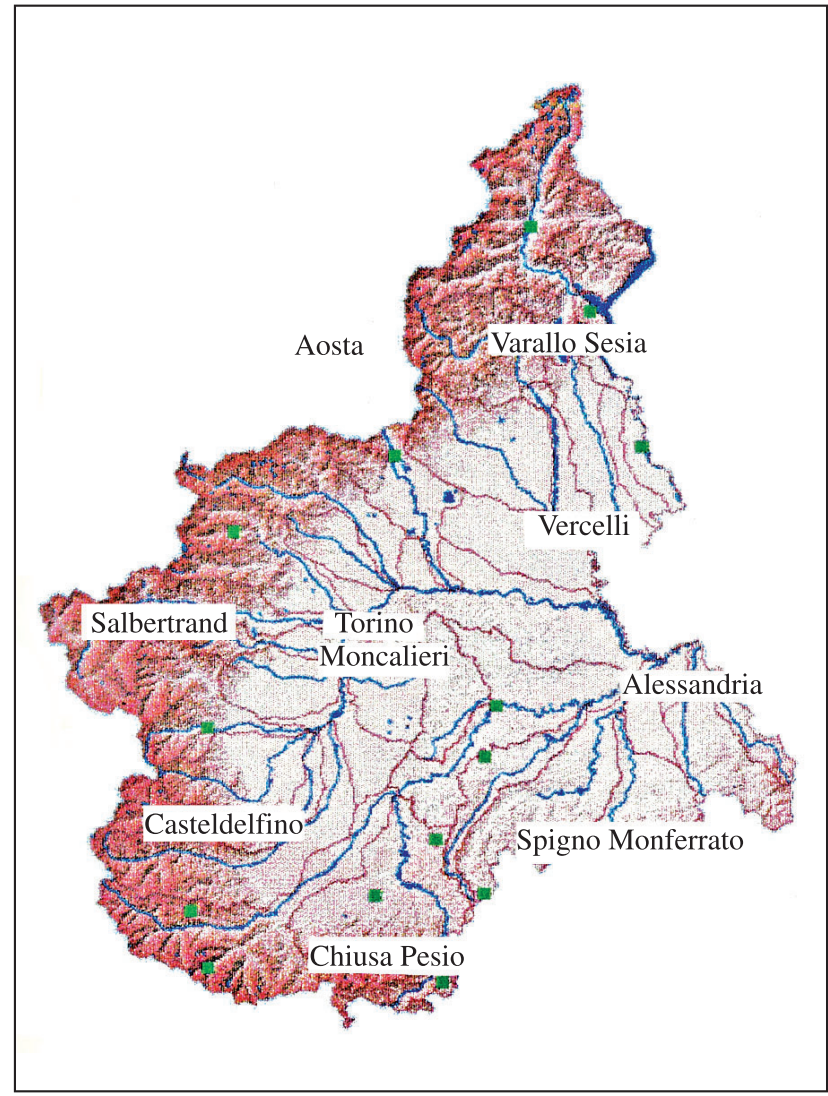

Fig. 1. Chart of the stations of «Ufficio Idrografico» chosen to create our rainfall indexes.

of registration or poor accuracy of historical records), we had to reject many of them. We did a further reduction of the number of stations considered by grouping (after a comparison of experimental data) some stations (like Torino and Moncalieri) to obtain a uniform distribution in the Region. Furthermore, studying long periods, the final choice of the stations (shown in fig. 1) seemed expressive for our purposes.

The analysed periods are 1931-1950 and 1980-2000. The first one was chosen because of the quantity of experimental data (many stations started their activity in this period) and their importance, related to the small immission (in the period 1931-1938) of pollutants in the atmosphere. Until 1950, in fact, in Torino the heating systems were working using coal or wood, but they were fewer than now. The second fact is that the number of cars or similar means of transport was limited (it was not uncommon to use animal traction). It should be possible, in 
that way, to see the possible effects of pollutants or, anyway, of a different thermal situation of the atmosphere.

\section{Rainfall index}

In order to find extreme events, we decided not to study the mean quantity of rain in a period, because it is possible to increase it having a small quantity of rain every day (without floods). So, we decided to analyse the accumulated precipitation, in millimetres, for a period of 24 and $48 \mathrm{~h}$. We did not consider greater periods of time, because it is rare (in the chosen periods, extreme events of more than two days of precipitations, as the one of 13-16 October 2000, have been, in total, less than 10) to have great precipitations on the third day. Besides, we considered, as intense events, the ones originated by a large quantity of water in a short time.

We created an Absolute Intensity Index (AII) for 24 or $48 \mathrm{~h}$, given by

$$
\begin{aligned}
\mathrm{AII}_{1} & =\frac{\mathrm{mm} \text { rain }}{24 \mathrm{~h}} \\
\mathrm{AII}_{2} & =\frac{\mathrm{mm} \text { rain }}{48 \mathrm{~h}} .
\end{aligned}
$$

To see only the extreme events, we fixed a lower limit under which the index was considered equal to 0 . The threshold limit was chosen to be $6 \%$ (for $24 \mathrm{~h}$ ) and $7 \%$ (for $48 \mathrm{~h}$ ) of the mean of the annual precipitation quantity along the period considered for each single station. This choice offers at least two advantages: we obtained an optimum number of events for each period and, furthermore, we found an index not linked with local climatological factors. In fact, the threshold values, moving from one station to a different one, cancel the differences that exist among them. We can point out, using the AII, the increase in millimetres of water fallen in each single event, even if it is difficult to see how this could be meaningful during the comparison among the different stations. That is why we created a Normalised Intensity Index (NII), referred to the mean annual value of the period considered, cal- culated as mean of annual means

$$
\mathrm{NII}=\frac{\text { AII }}{\text { mean annual value for the period }} .
$$

In this case, if in the last 20 years we have had less rain, the value of NII increases giving significance to the single events. In this case too, the thresholds chosen are equal to those of the AII.

\section{Conclusions}

To see what has happened in the 40 years considered and not having all the data of the first 20 years (we had all the data just for the period 1931-1941), we have divided the periods considered into groups of 11 years, superposing them if necessary. In order not to have any problems with the threshold limits in the different periods, we decided to use a new one (equal to the highest of them), that did not create any problem using the NII, because we are referring to percentages.

Figures 2 and 4 show the number of events with AII with values different from 0 for a period, respectively, of $24 \mathrm{~h}$ and of $48 \mathrm{~h}$. Furthermore, figs. 3 and 5 highlight the number of events with NII different from 0 for periods of $24 \mathrm{~h}$ and 48 $\mathrm{h}$ respectively. Our analysis shows an increase, in the last period considered, in the number of events, particularly intense ones. For nearly all the stations, in fact, mainly in the period 19902000 , we can see an increase in intense events, though it rains less than before. It is important to remember here that, during the flood of 15-16 October 2000, that provoked so much damage and so many deaths, we had in many areas more than $500 \mathrm{~mm}$ of water in 3 days.

Considering the causes of those types of rainfalls, the interest in the GEOFIT group of «Università degli Studi di Torino» is focused on the study the influence of Suspended Particulate Matter (SPM) in the events of intense precipitations (Bacci et al., 1983). We can say, using the data of 30 years of experimental measures, that the granulometric distribution of inorganic solid SPM with diameter of less than $10 \mu \mathrm{m}$ has changed. 


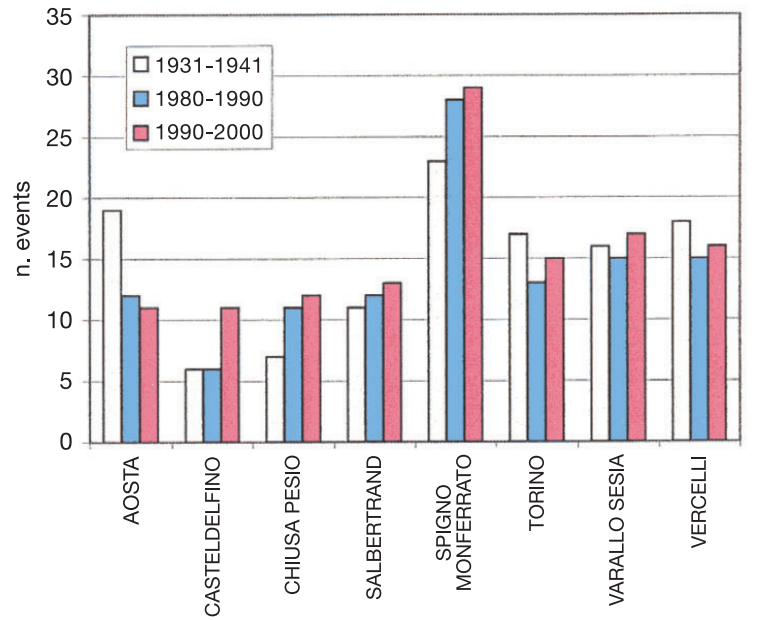

\begin{tabular}{|l|c|c|c|c|}
\hline & $1931-1941$ & $1940-1950$ & $1980-1990$ & $1990-2000$ \\
\hline AOSTA & 19 & 16 & 12 & 11 \\
CASTELDELFINO & 6 & & 6 & 11 \\
CHIUSA PESIO & 7 & & 11 & 12 \\
SALBERTRAND & 11 & & 12 & 13 \\
SPIGNO MONFERRATO & 23 & 13 & 28 & 29 \\
TORINO & 17 & & 13 & 15 \\
VARALLO SESIA & 16 & & 15 & 17 \\
VERCELLI & 18 & 15 & 15 & 16 \\
\hline
\end{tabular}

Fig. 2. Number of events of $24 \mathrm{~h}$ with AII different from 0 .

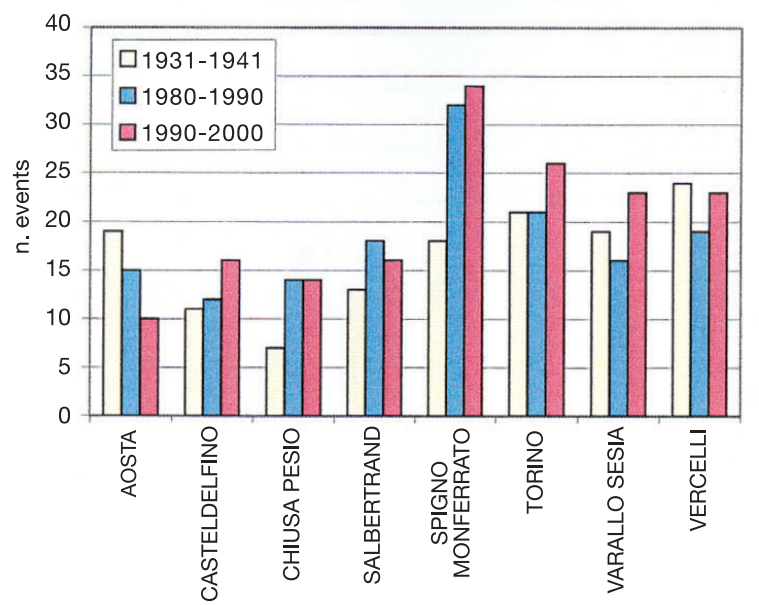

\begin{tabular}{|l|c|c|c|c|}
\hline & $1931-1941$ & $1940-1950$ & $1980-1990$ & $1990-2000$ \\
\hline AOSTA & 19 & 21 & 15 & 10 \\
CASTELDELFINO & 11 & & 12 & 16 \\
CHIUSA PESIO & 7 & & 14 & 14 \\
SALBERTRAND & 13 & & 18 & 16 \\
SPIGNO MONFERRATO & 18 & 17 & 32 & 34 \\
TORINO & 21 & & 21 & 26 \\
VARALLO SESIA & 19 & & 16 & 23 \\
VERCELLI & 24 & 15 & 19 & 23 \\
\hline
\end{tabular}

Fig. 4. Number of events of $48 \mathrm{~h}$ with AII different from 0 .

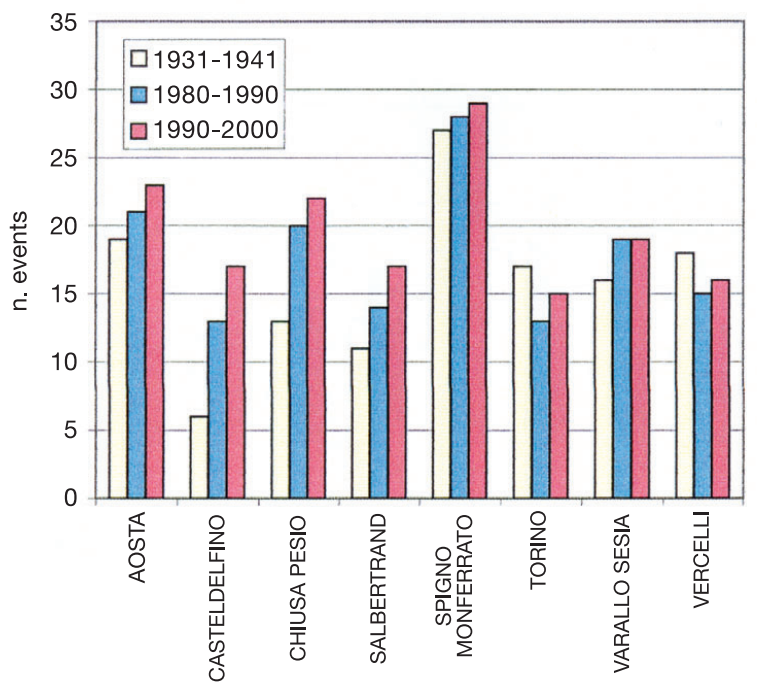

\begin{tabular}{|l|c|c|c|c|}
\hline & $1931-1941$ & $1940-1950$ & $1980-1990$ & $1990-2000$ \\
\hline AOSTA & 19 & 16 & 21 & 23 \\
CASTELDELFINO & 6 & & 13 & 17 \\
CHIUSA PESIO & 13 & & 20 & 22 \\
SALBERTRAND & 11 & & 14 & 17 \\
SPIGNO MONFERRATO & 27 & 14 & 28 & 29 \\
TORINO & 17 & & 13 & 15 \\
VARALLO SESIA & 16 & & 19 & 19 \\
VERCELLI & 18 & 15 & 15 & 16 \\
\hline
\end{tabular}

Fig. 3. Number of events of $24 \mathrm{~h}$ with NII different from 0 .

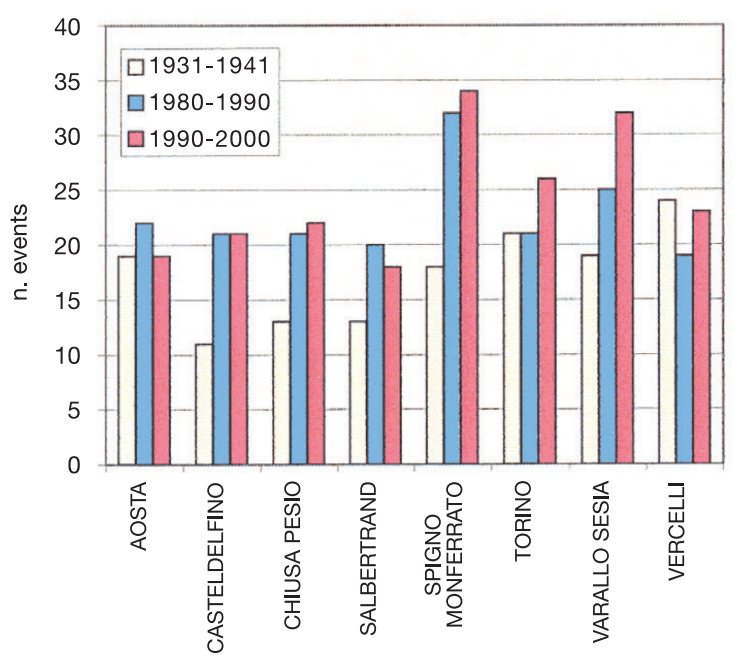

\begin{tabular}{|l|c|c|c|c|}
\hline & $1931-1941$ & $1940-1950$ & $1980-1990$ & $1990-2000$ \\
\hline AOSTA & 19 & 21 & 22 & 19 \\
CASTELDELFINO & 11 & & 21 & 21 \\
CHIUSA PESIO & 13 & & 21 & 22 \\
SALBERTRAND & 13 & & 20 & 18 \\
SPIGNO MONFERRATO & 18 & 16 & 32 & 34 \\
TORINO & 21 & & 21 & 26 \\
VARALLO SESIA & 19 & & 25 & 32 \\
VERCELLI & 24 & 16 & 19 & 23 \\
\hline
\end{tabular}

Fig. 5. Number of events of $48 \mathrm{~h}$ with NII different from 0 . 


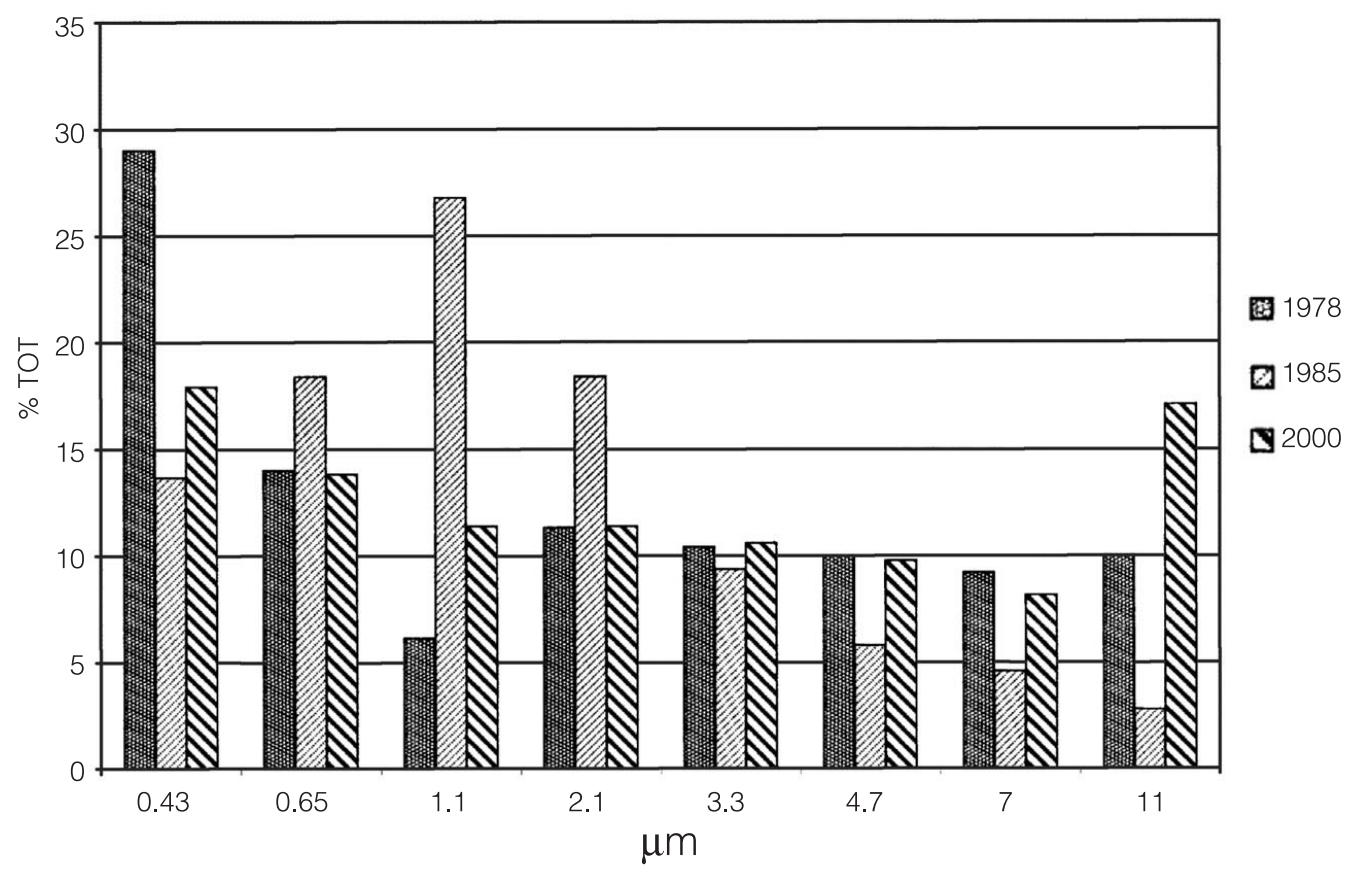

Fig. 6. Granulometric breakdown of particulate matter in 1978, 1985, and 2000.

Table I. Cut-off diameters for each single stage of non-viable Andersen Cascade Impactor.

\begin{tabular}{cc}
\hline \hline Stage & $\begin{array}{c}\text { Cutt-off diameter } \\
(\mu \mathrm{m})\end{array}$ \\
\hline 0 & $\geq 11$ \\
1 & $7-11$ \\
2 & $4.7-7$ \\
3 & $3.3-4.7$ \\
4 & $2.1-3.3$ \\
5 & $1.1-2.1$ \\
6 & $0.65-1.1$ \\
7 & $0.43-0.65$ \\
\hline
\end{tabular}

Figure 6 shows the results of 3 representative measures of the years 1978, 1985, and 2000, mean of several measures done in the same period of the year with stable weather conditions. The instruments used for those measures are 8 stages non-viable Andersen Cascade Impactors (Andersen, 1958; Vaughan, 1989), whose cutoff diameters are shown in table I. This type of instrument gives us the possibility to study the granulometric repartition of SPM between 0.43 $\mu \mathrm{m}$ and $10 \mu \mathrm{m}$.
It is possible to see that the breakdown for the year 2000 (confirmed by many measures in 2001 ) is more flattened than before and it is quite common in outdoor measurements.

We think that this might have influenced the production of raindrops in such a way to obtain an increase in intense rain events, considering other causes too. Among them, it is important to consider the energy involved in the condensation process and the humidity of the air in different climatological conditions.

In addition, we are again studying the chemical and physical characterization of solid inorganic particulate matter in urban and rural areas to understand the degree of influence of this in the condensation of water vapour in the atmosphere.

\section{REFERENCES}

ANDERSEN, A. A. (1958): A new sampler for the collection, sizing and enumeration of viable particles, J. Bacteriol., 76, 471-484.

Annali Idrologici: Ministero dei Lavori Pubblici, Servizio Idrografico (Istituto Poligrafico dello Stato, Roma).

Bacci, P., A. Longhetto, G. Marcazzan, A. Piano, F. Prodi, C. SABbioni and A. Ventura (1983): Aerosol 
characterization in a Po Valley site, in Proceeding of the Gesellschaft für Aerosolforschung Meeting, J. Aerosol Sci., 14 (3), 222-225.

DiodATO, N. (1999): Ricostruzione storica di eventi naturali estremi a carattere idrometeorologico nel Sannio
Beneventano dal Medioevo al 1998, Boll. Geofis., 22, 5-39.

VAUGHAN, N.P. (1989): The Andersen impactor: calibration, wall losses and numerical simulation, J. Aerosol Sci., 20 (1), 67-90. 